\title{
Narrative Norms in Written News
}

\author{
EbBe Grunwald
}

\begin{abstract}
News writing is organized in accordance with a norm usually visualized as an inverted pyramid. The purpose is to support a focus to tell the reader, which information is the most actual, important and relevant.

News is also stories about selected factual events narrated and re-narrated by sources and journalists. The involved communication acts of journalism are important tools in the hands of the writer by means of which news is made understandable, credible and interesting. The tools are used differently in papers and genres, and they are still influenced by the continuous competition among the daily papers in the market.

The purpose of this article is to explore, punctually demonstrate and explain the narrative norms that govern the writing of news. It defends the point of view that the contextual conditions of this journalistic activity is developing narrative modes and voices that fit into the ongoing fight for the attention of a treacherous public.
\end{abstract}

Keywords: written news, newspapers, use of language in journalism, narrative norms, communication acts of journalism

\section{Introduction}

The content of standard news is traditionally divided into four main groups (cf., e.g., Meilby (1996): 254-255): (1) introduction, which contains the most important of the new information, (2) background, which adds perspective to the new information, (3) documentation, which most often consists of quotations and (4) information, which could be left out, strictly speaking. This is also called 'filling'.

The division reflects a general principle of order most often referred to as the 'inverted pyramid'. This principle concerns priority, which means that the order of information is governed primarily by news values: the more important information precedes the less important from the beginning to the end of an article. The principle does not tell us, however, how and why news texts actually are or have to be written in certain ways - or what differences turn up within and between the writing practices of the single papers and their journalistic genres. There is a gap between the general news criteria, the priority principles and the final linguistic and narrative shaping of the output: the concrete journalistic article.

Ebbe Grunwald, Associate Professor, Dept. of Journalism, University of Southern Denmark, Campusvej 55, DK-5230 Odense M, ebg@journalism.sdu.dk 
In the Scandinavian countries - especially at the schools and departments of journalism - questions about how to linguistically perform the article outputs of journalism have been dealt with for several decades by researchers and educators of journalistic writing. Their intentions have been to develop knowledge about the structure and function of all sorts of journalistic texts in order to make it possible for future professional writers to reflect critically the frames and goals of the specific acts of journalistic writing performance. Against this critical and self-critical background, generations of journalists have improved their abilities to produce articles, which are as good and powerful as possible - from the readers' points of view. This kind of research tends to have a normative aim as far as it investigates the linguistic and narrative conditions of successful journalistic communication, i.e. the mechanisms and structures that make the texts of journalism understandable, reliable, vivid and interesting.

To be mentioned as examples are several books from Sweden, containing analyses and linguistic advises for journalists: Alfvegren (1965, 1973, 1976), the classical book of rhetoric in the mass media, Nerman (1973), analyses of genres, trends of writing style and language usage in journalism: Hultén (2000), Hultén (1990), Thurén (1992) and most recently an empirical investigation of genres and text structures in the treatments of five strikes in leading papers of Sweden 1879-1996 by Rahm (2001). In Norway you can find a book about rhetoric for journalists by Roksvold (1989), and analyses of specific journalistic genres by Jo Bech-Karlsen (1984, 1988, 2000). In Denmark the journalistic usage of language has been investigated and linguistic advice developed by Grunwald et al. (1992), Veirup et al. (1973) and most recently by Hvid (2002) and Skyum-Nielsen $(2002,2003)$.

In order to make further contributions to the theoretical framework of these approaches and strengthen their empirical foundations, I systematically analysed a sample of 1,781 news articles published during the first week of August 2001 in five leading national papers: Berlingske Tidende, Politiken, Morgenavisen Jyllands-Posten, B.T. and Ekstra Bladet.

All paragraphs in the material consisting of articles were investigated to determine the type of the communication act (cf. below). The focus of the analysis was on the combination of different communication acts in the single article. Its aim was to discover and describe the mechanisms of the narrative activity that follows the uses of news criteria and priority principles in the production of news. The question was not which types of news were chosen to be presented but how they were actually written and why.

My exploration has two sources of inspiration: the theory of speech acts, which points to a relation between changing the language and changing the world, and the narratology, which analyses the construction and function of texts. Especially the concepts of order, mood and narrative voice play a role in my analysis. Approaches to written texts in general can be found within branches of language philosophy and literature research, which refer to these sources (e.g. Austin (1962), Genette (1972, 1988), Searle $(1970,1971))$. The combination and implementation of these theories into the analysis of samples of texts produced by journalists for media purposes has not been made to date.

A newer, very interesting, analysis from Finland of the quotations in front-page journalism shows how quotations within articles are used for several purposes: 1) to confirm the news value of an article, 2) to evaluate problems established in the text, 3) to communicate criticism in order to reinforce conflict and drama, 4) to communicate subjective experiences formulated by the sources, 5) to communicate a sense of closeness to them in time and space and 6) to communicate attitudes, interpretations and solutions to the problems presented, cf. Nylund (2003). 
In this article I shall go a few steps further into the realm of linguistic and narrative performance and demonstrate the different functional aspects inside the news by looking more closely at the texts in which the quotations are embedded. In this way I shall expose the contexts of quotations and analyse the narrative anatomy of the news article.

\section{A Flow of Shifting Speech Acts}

An article is in the first formal step described as a typographical unit in the newspaper which, expanded to its maximum, contains ordinary text and a row of paratextual functioning elements such as headline, subheading, small subheads, photos, photo captions, graphics and text boxes with factual information. The ordinary text of an article, the size of which can be measured in, e.g., column lines, may - in an aristotelic and simple way - be divided into a beginning, middle and end, cf. Aristotle (1965).

In the next step an ordinary text in an article is viewed as a linear structure composed of utterances, each of which functions as a speech act or an act of communication. In this context the quotation is a specific act performed by a narrator. I shall return later to the way quotations are like - and differ from - the other journalistic acts of communication, which constitute the linear structure of the ordinary text.

Some of the differences show up when you characterize the actions by verbs such as the following infinitives: quote, report, sum up, refer to, describe, announce, characterize, evaluate, argue, mean, recount. This list could be extended and adjusted to concrete analyses. Now, if we supply each verb in this list with its logical subject, we come up with a series of simple sentences which are I quote, I report, I sum up, I refer to, I describe, I announce, etc. It should be clear that the $I$ refers to a hidden subject of the shifting acts of communication, which the journalist performs in his or her role as communicator and narrator.

The hidden $I$ has furthermore - during its performance of journalistic narration - a principal interest in the production of true, relevant, readable, understandable, reliable and interesting information. One generally can not observe the narrator of printed journalism. The role is nevertheless indirectly expressed at different levels in the text: in its linear structure, in the way the story is told and in the choice, type, variation and extent of the different acts of communication of which an informative text is made up.

What we have described as acts of communication is typically put into practice in the specific paragraphs that constitute the formal sequence of an article. The way the journalist performs his or her narrative acts changes typically from paragraph to paragraph. An essential part of an empirical investigation of articles is going through the texts and determining the different communicative functions of the paragraphs. Here, the list of verbs is a central characterizing tool.

\section{The Quotation as a Verbal Copy}

As an example we will look closer at the way in which the journalist's narrative role is performed in one of the most common acts of communication in journalism: I quote.

You may say that the journalist is the actor, in the sense that he chooses the words he considers appropriate to communicate - the words expressed by the source. In reality as well as in grammar, the journalist is the subject of the speech act expressed by the verb to quote. But the actual wording of a quotation made by the journalist is modelled on, or reflects, the words that the source used in the original statement. The journalist's quotation is a copy of the words of the source, so to speak. 
It is a well-known fact that the journalist always chooses to reproduce parts of a statement as quotation, but the chosen material is in principle a true copy of the words selected by the journalist and used by the source. In practice the copy may differ by degrees from the original, especially if the original statement is oral and the reproduction - as in the material of this investigation - is written. However, these minor differences do not change the fact that the journalist - in the process of quotation and as a narrator - is operating in the purest mimetic mood of communication.

The concepts of mimesis and diegesis are derived from Plato, who assigns a critical function to them ${ }^{1}$. Here they are used as descriptive designation of ways of telling a story. With Genette (1972), you may say that the narrator regulates the level of distance to the subject matter by his choice of narrative mood. By choosing a mimetic mood the narrator comes very close to the source. By choosing a diegetic mood the narrator increases the level distance to the source.

So, the quotation in journalism is a verbal imitation of that part of the investigated reality, which is available as language. But this imitation takes place on the conditions of language. By using a quotation the journalist shows the statement of a source by selecting and copying some of the words in it. With this copy the journalist documents that the words in a specific situation are said in a certain way, which is expressed by quotation marks, colons and introductory verbs. Of course this also means that the risk of making mistakes during the act of communication is real. Quotations can be wrong.

If we look at the total - and perhaps still incomplete - arsenal of journalistic acts of communication it is possible to distinguish between two types:

The first type includes to report, to quote, to refer to and to describe. These acts have the - mainly mimetic - purpose of documenting what is said by the sources (to report, to quote), who the sources are (to refer to), and what the journalist, by observation, experience or otherwise, has made himself sure is true (to describe). This type of journalistic communication act is hereafter called the documentative type.

The second type includes to announce, to sum up, to tell, to explain, to argue, to evaluate, to characterize. These are acts where the journalist - in a diegetic way chooses to increase the distance to his subject matter, and - as a narrator - go into the text to co-ordinate information and to express the central points of the story. This is called the summarizing type of journalistic communication act.

The play and variation between these acts of telling - the journalistic parallel concepts of which are the well-known showing vs. telling ${ }^{2}$ - has some consequences for the relationship between the article's narration time and its narrated time, which will be considered in the following section.

\section{The Narrative Order of News}

The ordinary text of an article can be considered as a unity, the elements of which are arranged in linear, temporal sequences. The size of sections directly determines the length of narration time or reading time, i.e. the time it takes to tell, retell or read a text of a given length. The narration time as a phenomenon is tied to the physical linguistic expression of the story.

Narrated time is the story's real time. It is a phenomenon that has to do with the content matter. Broadly speaking, the narrated time of a story is a matrix that reaches into the past, present and future. Chronological order in a text is a result of the fact that the beginning, middle and end of the text follow this temporal matrix.

However, the narrative order of a journalistic news article often seems to be characterized by breaks in the chronology that otherwise determine the logical relationship 
between the events of the story. The structural principle that transforms the narrated chronology is importance. This means that the described events and their elements are ordered by priority.

So, in journalism narrated time has a free and independent relationship to the narration time, but on the other hand it is dependent on the variable mood of narration: In a few lines, say ten, a narrator can move diegetically and with distance to his subject matter through many years, and in the next ten lines he can choose to mimetically copy most of the details in a single scene whereby the narration almost comes to a halt. In the latter case the relationship between the narration and the narrated is in balance.

The time of narration and reading in journalism must be assumed to vary around an average, the objective base of which is a number of linearly ordered words or column lines. To say that the article is linearly ordered means that its individual elements are dependent on being told or read in a specific temporal order for full understanding. This dependence is partially broken in the relationship between the paratexts of the article (headlines, subheadings, photos, photo captions, etc.). But in order to produce meaning the ordinary text in an article must be handled according to its linear principle. It cannot be read backwards or by a random moving around between its parts. Texts on the Internet are currently trying to escape from this principle (cf. the principle of non-linearity of Internet texts), but that is a different story.

Printed and paper-distributed texts function in a relatively firm framework of temporal dependencies. This very relationship is used in the construction of the journalistic text in which the writer always knows where the reader begins.

Summing up the analysis of the possible narrative structure of news articles can be done by way of Figure 1, which is based on several assumptions, including the assumption that a news article spans 70-90 column lines.

The figure links the concepts of the inverted pyramid, acts of communication and the mood of narration:

Figure 1. Form, Narrative Acts and Narrative Order in News

\begin{tabular}{|c|c|c|c|c|c|}
\hline \multicolumn{3}{|c|}{ The form } & \multicolumn{3}{|c|}{ Narrative structure } \\
\hline Sections & $\begin{array}{l}\text { Column } \\
\text { lines }\end{array}$ & Priority & Communication act & $\begin{array}{l}\text { Type of commun- } \\
\text { ication act }\end{array}$ & $\begin{array}{l}\text { Mood of } \\
\text { narration }\end{array}$ \\
\hline I & $1-10$ & Introduction & Announce & \multirow[t]{2}{*}{ Summarize } & \multirow[t]{2}{*}{ Diegetic (tell) } \\
\hline II & $10-30$ & Background & Sum up & & \\
\hline III & $30-60$ & Documentation & Quote, report, refer & \multirow[t]{2}{*}{ Document } & \multirow[t]{2}{*}{ Mimetic (show) } \\
\hline IV & $60-70$ & Filling & Quote, report, refer & & \\
\hline
\end{tabular}

In an earlier study, Grunwald (2003), I have verified the assumptions of Figure $1 \mathrm{em}-$ pirically. In brief, the conclusions of these investigations are as follows:

1) There exist narrative structures in notes and articles with a by-line. Narrative structures differ from structures dictated by the inverted pyramid and reflect clear orders and shifts in moods of narration.

2) The elements of the narrative structures are journalistic acts of communication, the rank order of which is consistent for notes and articles respectively.

3) Most news (67.2\%) is communicated as short notes with or without signature. The rest $(32.8 \%)$ is longer articles each with a by-line that identifies the writer with a name. 
4) The dominating acts of communication in the material are: to sum up (25\%), to announce $(21 \%)$, to quote $(21 \%)$, to report $(20 \%)$. The remainder $(13 \%)$ include the remaining seven acts of communication (cf. above, p. 66) and Tab. 1, p. 69).

5) In articles with by-lines there seems to be a balance between diegetic and mimetic moods of narration (42.4 and $46.4 \%$, respectively). As for notes, this balance has moved in the favour of diegesis (53.8 as opposed to $31.2 \%$ ). The explanation of this difference is that articles opposite notes have more space for documentative (mimetic) acts.

This predominantly quantitative analysis of journalistic narration should be supplemented with qualitative explorations of cases. They will be able to show which tools writers use to vary the narrative pattern of communication. I shall go further with this in the following section. Important questions are: How are the acts of communication actually written? By which linguistic and narrative tools do they meet their goals? In what way are the different voices of the news narrator expressed? But first I have to elaborate some methodical points.

\section{The Systematic Selection of Cases}

In the following sections I shall use 34 text examples as a basis for qualitative investigations and documentation of central narrative categories and subcategories in written news journalism (cf. Fig.1). The selection of the examples has taken place in several steps and against the background of different considerations concerning the purpose of this part of the analysis.

The selected examples must show how journalists actually use their linguistic and narrative tools when performing the most frequent communication acts during the processes of writing news. The results from the quantitative analysis of the published material answer this question only to a certain extent. You can demonstrate the central and most frequently used communication acts as categories in news journalism, but you do not yet know how they are performed or how they function.

The selected examples must supply the quantitative information with information based on observations of the usage and narration of journalism. The methodical problem is here one of validity, i.e. the problem is to capture, demonstrate and specify linguistic and narrative functional details in the central categories and subcategories by means of selected, relevant and convincing examples from the material. In order to achieve and go through this point in the analysis, the previously mentioned quantitative registration and coding of the empirical material must be supplied with observations based on close reading and understanding of the usage in selected examples.

When I chose the period of investigation (cf. p. 64), I took into consideration the fact that linguistic and narrative categories change relatively slowly over time. The variation from day to day or week to week of the contents and themes of the daily papers did not seem important for the specific purpose of my investigations. On the contrary a whole week seemed necessary, because of the variation during a week of the way the most common genres are used: From Monday to Thursday you commonly find standard genres and from Friday to Sunday you find the longer genres such as background articles, longer portraits, feature articles and so on. In order to get access to these variations in genre and narration, the selection of a whole week seemed reasonable.

In the period of investigation the total number of published articles in the five daily papers is 3.991 items. Forty-five percent $(=1.781$ items $)$ are recorded as news articles, 
i.e. articles, which are not reports, portraits, interview or feature articles. Neither are they mentions, advance publicity, reviews, analyses, commentaries, editorials, columns, background articles or updating of current affairs. The selected empirical material instead represents the daily flow of articles, which build on statements or announcements of one or few sources, and the contents of which are current and new.

As for the quantitative analysis - the empirical material consisting of news articles was selected, analysed and coded in the period, when the articles were published. Three coders performed the work of categorizing and coding. In order to secure a high level of reliability in this part of the process the principles of the analysis and the definitions of the categories were continuously discussed, especially the categories of communication acts. The most frequent were - as mentioned on p. 68: to sum up, to announce, to quote, and to report.

Articles are built using paragraphs, and all paragraphs were categorized and coded. Paragraphs with references to statements made by named sources were considered quotations or reports. References are made directly in the paragraph or indirectly in the textual context of the paragraph. Quotation marks were taken as genuine signs of quotations. The reports do not have marks, but rather references to named sources.

Paragraphs without references to sources were considered summaries or announcements made by the journalistic narrator of the news. In summaries or announcements, the narrator frames what the news story is all about. This framing is commonly supported by statements by the named sources. A summary may contain several main points in a subject, whereas an announcement generally contains a single point, which is the new information.

The resulting numbers of the analysis of the communication acts in the coded material are shown in the following table:

Table 1. Frequency Numbers for the Use of Communication Acts in News Material

\begin{tabular}{lcc} 
Communication acts & Numbers & Percent \\
\hline Reports & 1.955 & 20 \\
Quotations & 2.085 & 21 \\
Summaries & 2.530 & 25 \\
Announcements & 2.044 & 21 \\
The 7 other categories & 1.235 & 13 \\
Total & 9.849 & 100 \\
\hline
\end{tabular}

The data file was constructed in such a way that I could easily trace examples of the communications acts in, e.g., the first few paragraphs of an article, especially the lead paragraph. I only had to use a simple cross-classification procedure. All articles with, e.g., a summary in the lead paragraph, could be found in this way, isolated and exposed for close examination. The same could be done with other communication acts in the lead or other paragraphs.

The purpose was to find documentation of the narrative categories shown in Figure 1 and determine their subcategories by means of linguistic and narrative investigations. The result of the quantitative analysis told me with great precision where to read in the five papers from the selected period. The final selection of examples was made by means of a reading and evaluation process. The course and conclusions of this qualitative and evaluative procedure are demonstrated in the following sections. 


\section{Cases of News Narration}

I have selected cases from the most frequent categories of communication acts. They show how especially the lead paragraphs are managed in notes and articles. By bypassing the quantitative pattern of communication and looking directly at the texts you may have a better opportunity to characterize the varying moods and voices in the narration of news.

Behind the formal predictability, which dominates much of the material, my investigations show how communication acts are reinforced and the messages made vivid and visual with narrative tools such as concrete and understandable words, metaphors, third person's point-of-view and sudden shifts of mood and voice. By means of these tools, news writing may lose its well-known anonymous character and get personal instead.

\section{(1) Announced News}

The quantitative analysis points out announcements as the most frequent act of communication in the first paragraph of notes and articles. In an announcement the writer gives news information without reference to the source. The narrative elaboration of an announcement is shown in the angle of the new information and in the background information that the journalist chooses to link to the new information:

When the new school children begin on Monday the traffic police will also be out in the street to support the many new road users. (Berlingske Tidende, 6.8.01, p. 5)

The news information in this first paragraph is (1) that the traffic police will be out to support. This is repeated in the paratextual headline of the article ('Police ready on school roads'). The information is combined with two more or less-known pieces of background information: (2) this year's new batch of school children begins on Monday, and (3) there are many new road users among the children.

The result of the linguistic combinations - particularly of verbs of action - is a story with an angle that focuses on the police performing the role of protectors and communicators of safety among a weak group in traffic on the first day of school.

Against this background a journalistic story communicated as an announcement is considered to be an independent combination of information, which in relation to the context may be known or unknown.

Such a combination presupposes that the communicator has taken on the role of the narrator who realizes the original and entire contents of a sequence that contains a chosen angle and possibly supplements the angle with emphatic elements ("will also be out', 'many new') and positive connotations ('support').

A news report may sometimes have a solid and boring form such as in the following telegram note, where the sentence begins with a great deal of background information expressed by way of prepositional phrases:

With ten official international matches without defeat to his name, among other things, coach for the Danish national team, Morten Olsen, was elected Danish football coach of the year 2000/2001. (Jyllands-Posten, 6.8.01, JP-Sport, p. 1)

The problem here is that the narrative possibility, which might be the story of Olsen's election, is pushed into the background in order to make room for all the information that surrounds it. 


\section{(2) Explicit Narration of News}

In the tabloids and especially in Ekstra Bladet you can often see variations from the common daily news flow and a less restrained joy of telling, as seen in the following use of a third person point of view:

Freddy Blak has had enough of usury. In a few weeks the Danish EU politician will send a letter to the Italian EU commissioner of competition, Mario Monti, with a demand for an investigation of all European telecommunication companies. (Ekstra Bladet, 7.8.01, p. 7)

But in the journalism of Politiken we also find narrated news, in which the writer has taken the spectacular content of a story and placed it at the beginning of the first paragraph or sentence:

No more stirring the soup of activation. The remaining 1,000 young Copenhageners under 25 who are still dependent on social security benefits will be given the decisive push out into the labour market. (Politiken, 6.8.01, p. 2)

The example contains a descriptive metaphor, which explicitly points to the fact that a narrative journalistic subject is active. In this case it is hidden, but indirectly present as a way of negatively understanding the process of activation of the unemployed.

\section{(3) Summaries}

The summary is a more complex act of communication than the announcement, because the communicator in a summary has to keep track of several elements that are temporally displaced:

In the early summer Viasat tried to convince a large number of long-time customers that the time had come to replace the old analogue satellite receivers with new ones.

The company's phone sellers argued that TV3 would very soon change to strictly digital transmissions, and that customers had to buy a new receiver if they wanted to be able to see TV 3 and $3+$ in the future.

The only problem was that this was not true. TV3 and $3+$ had not at that time or even yet - made up their minds as to when the transition to digital transmission will take place. (Berlingske Tidende, 6.8.01, business supplement, p. 12)

The narration in this piece has a predominantly diegetic mood: The narrator moves around in a story that spans several months. As a result the pace of the narration is high in the beginning, but it nearly comes to a standstill in the report and communication of the details of the untruthful phone sellers. Out of this combination of information a story emerges about (too) clever, fast and hard-core marketing of new IT products.

The temporal extent of the narrated content of a summary enables the writer to focus sharply on details in the communication. In this way he takes a stand and shares the indignation of the readers. This attitude may or may not have come from the source:

30,962 times in this year's first quarter alone elderly Copenhageners had to wait in vain for municipal domestic help. This is the amount of times the municipal domestic help corps cancelled a planned visit. And there is no financial compensation.

Minister of Social Affairs Henrik Dam Kristensen now wants to stop this in all municipalities of the country. In the future it will cost money to cancel a visit. (Politiken, 8.8.01, p.1) 
The summary has a built-in possibility of complexity that as a consequence may increase the information density of the news text. In this case the writer must - as just demonstrated - be able to guide the reader through each phase of an independently expressed summary of the details. If not, the 'Civil Service style' offers cut-and-dried elements that eliminate all possible narrative intentions from the communication - and ultimately perhaps even the reader.

The following example shows how the genitive form and prepositional phrases at the grammatical level dominate this style of writing:

The community of hospitals in the Copenhagen region $(\mathrm{H}: \mathrm{S})$ support Rigshospitalet in its decision to restrict the access of relatives to visit a severely brain-damaged 35-year-old woman.

Already yesterday H:S received a report of the case from Righospitalet, which for five weeks has upheld the visitation restrictions under threats of police. (Berlingske Tidende, 7.8.01, p. 2)

\section{(4) Quotations and Reports}

Quotations are verbal and narrative copies of words uttered by sources. Quotations of statements are unusual in the first paragraph of an article. When a quote occurs, it is usually because it expresses a distinct attitude of the source in a precise language. In this way the reader is quickly guided to the main theme of the story:

"We got knocked and kicked around quite a bit, but I think the players have forgotten that already. As long as we score the goals and win, these things are soon forgotten". These are the words of Brøndby coach Åge Hareide, who is not worried for his players before the Lyngby-match although the UEFA Cup match is still in their legs. (JyllandsPosten, 12.8.01, p. 14)

The attitude of the source can be reinforced if the writer as a narrator chooses to focus on single words in a statement:

"Shocking". "Scandalous". The chairman of the Liberal Party, Anders Fogh Rasmussen, was aiming at the situation for elderly people in Copenhagen, when he presented his party's suggestion for a boost to senior citizen care yesterday. (Berlingske Tidende, 11.8.01, p. 4)

The quotation also may be put into a contextual framework of observations:

"My son is innocent!"

The hands of 73-year old Kirsten McCord are shaking as she welcomes B.T. to her small apartment in Herlev. (B.T., 9.8.01, p. 8)

It is not always possible to distinguish clearly between the attitudes of the source and those of the journalist. The transition from quotation to report may weaken the clarity at another level, and it can easily become uncertain what the source actually stated and what the journalist meant:

The Danish education system lags severely behind a number of other Western countries. So says the Conservative Party, which yesterday presented a detailed proposal for the education area, which - according to the party - will imply dramatic changes compared to the present situation. (Berlingske Tidende, 6.8.01, p. 5) 


\section{(5) Opinions in News}

Narrative openings of news articles may result in the explicit expression of the opinion or attitude of the writer. The writer is thus on a collision course with an established principle in journalism of not mixing one's own comments with reports in the same article. Not because it is a mix, but rather because it is difficult for the reader to see through this journalistic engagement.

In some newspapers, a personal and engaged communication of source statements can have the effect that doubts are raised about the credibility of the source. That is the case in the following piece, in which the choice of the verb 'claim' indicates - for no apparent reason - that the source is not only questionable but most likely quite unreliable:

The international human rights organisation Amnesty International now claims to be able to document that the coming Israeli ambassador, Carmi Gillon, is guilty of the death of at least one man under torture. (Ekstra Bladet, 6.8.01, p. 4)

The transitional government of Somalia (TNG) claimed yesterday that 8,000 Ethiopians have penetrated the country's borders of... (Berlingske Tidende, 9.8.01, p. 10)

A cholera epidemic is developing in central Russia, claims the correspondent of the newspaper 'Vesija' among others... (Politiken, 6.8.01, p. 8)

The negative connotations of the words chosen can help establish a critical attitude against the system as a whole:

For a month a dead man's body was allowed to rot in an apartment in Amager even though the domestic care system knew very well about the death. (Ekstra Bladet, 6.8.01, p. 6)

In the opposite way a positive personal engagement may invoke sympathetic attention - again through the choice of words with particular connotations:

'Mr. News', Steen Bostrup, had barely left the TV news room to enjoy his retirement before he was struck by serious illness. The former newsreader was taken to Rigshospitalet on Thursday night. (Ekstra Bladet, 7.8.01, p. 5)

The opinions expressed in news texts are created by evaluative or emphatic words. Through a series of linguistic choices the communicator signals a positive or negative attitude to the sources or the exposed event. An example of a negative attitude is seen in the following:

A morbid propensity of playing the one-armed bandit caused a 50-year old pathological gambler to commit two bank robberies and one post office robbery in Copenhagen. (Ekstra Bladet, 8.8.01, p. 10)

The above case differs from other cases, with the communicator showing a basic solidarity with the source and the criticism the source expresses:

Grill bar owner Søren Rasmussen, 37, Odense, is sick and tired of being robbed. In two years he has had 25 break-ins - surely a Danish record. (Ekstra Bladet, 12.8.01, p. 9)

Finally, there are cases in which the attitude toward the sources and their statements is expressed positively, bordering on the verbally applauding: 
Copenhagen Zoo today opens its doors for a sure visitor hit: a newborn striped tapir baby, indeed of the endangered caparison-tapir species. (Berlingske Tidende, 9.8.01, p. 15)

It is impossible to discourage American adventurer Steve Fossett. Five times he has tried to become the first man to fly solo around the Earth in a balloon. All attempts have failed. (Berlingske Tidende, 6.8.01, p. 10)

\section{(6) Metaphors}

The metaphor is usually considered an extraordinary poetic or rhetorical tool in texts. Metaphors are used, e.g., when writers need to attract readers' attention and communicate a special - perhaps quite new - aspect, which may add a new perspective to the subject or object of a text.

Modern research on metaphors ${ }^{3}$ has developed a broader concept and demonstrated that the systems of concepts we use to structure our thoughts and plan our actions are metaphoric by nature. For instance, a common 'argument' in our culture is something we either 'win' or 'lose'. We 'attack' our opponents and 'defend' our own 'positions'. We are hardly conscious of the fact that the entire vocabulary around the concept of arguing is based on metaphors of warfare. According to Lakoff and Johnson's (1980) analyses, the word 'argument' in our culture derives part of its meaning from the concept of war.

From this point of view metaphors are basic to the production of meaning and communication among people. They permeate the everyday language or the language of experience, which is the exact type of language journalists draw on in their writing - also about complex subjects.

One of the consequences of using the language of experience for communication is that several types of metaphors appear side by side in journalistic texts. There are the original, communication stimulating metaphors, the less original ones - the so-called clichés - and finally there are the nearly invisible metaphors we live by - metaphors that show that we act and think in particular ways and develop according to metaphoric concepts.

Clichés are deeply rooted in the language of the media. Journalists may relate critically to them, but they can hardly avoid them. They may also choose to make a virtue of their presence. A cliché - even though it is seen as 'noise' in the communication process - can add an element of recognition to a text. Through recognizable metaphors readers may identify the narrator's conceptual framing of his subject.

Apart from that the cliché is an opportunity for the linguistically agile journalist to make variations on the familiar and thus create surprises with the language.

The use of metaphors in newspaper texts demonstrates explicitly how the communicator is active as a narrator at the same time when the news reports are delivered.

A winner of a match is usually exposed and admired by the media. The victory ceremony is very often a long exposure in which the winner gets up onto a platform and receives a prize or trophy. Consequently, the metaphor to steal the show in the following extract seems to be a logical and necessary choice. It adds optics to the situation, which is a recognizable feature when talking about sports. On the other hand it would be obvious to classify it as cliché:

Dennis Jensen does not expect to steal the show today. The 32-year-old long distance runner simply is not good enough to do that. (Berlingske Tidende, 6.8.01, p. 5) 
The imagery of warfare permeates many discourses in modern society - for instance about competition on the market or when discussing politics. The following metaphors therefore seem natural and logical as tools of communication:

One of the world's fastest expanding newspapers, the free paper Metro, is ready to drop a grenade on the domestic newspaper market. (B.T., 10.8.01, p. 16)

After a relatively quiet summer the Liberal Party is now attacking the government on the areas of health and family. (Berlingske Tidende, 8.8.01, p. 2)

In spatial metaphors the vision of 'up' is connected to something strong, healthy or positive, while 'down' inherits weak, ill or negative values. In Lakoff and Johnson (1980), p. 14 ff. those metaphors are called 'orientational' and are described as having a base in our physical and cultural experience. As a language user you will hardly notice them, but they function as a common base of identification:

The indicators of the economy in the Euro region dropped to minus 0.36 in July from minus 0.03 in June. (Politiken, 6.8.01, p. 9)

The accusations against Real Madrid of having paid money under the table to several Spanish clubs now causes the president of the Spanish football union to react. (B.T., 6.8.01, Sporten, p. 7)

In rare instances you may find an original variation of a cliché-like metaphor in a news article:

One of the most popular coaches at Charlottenlund Trotting Course, Max Nielsen, has decided to close the stable door on 1 September after 20 years as a coach. (B.T., 10.8.01, Sporten, p. 8)

\section{(7) Metonymies}

It is common for a journalist to use observations or other types of sense experiences as a basis for communication - especially in the genres in which the writer as a journalist is present in a situation by which he meets and speaks to sources or attends an event. Registered or experienced details - if there are any - are together with statements central elements of the report, the interview and the portrait. The central imaginative tool is a metonymic one, whereby a small part may represent a whole or an effect may represent a cause. So, using very few words the writer may draw up pictures of persons or signal moods, such as in the following introduction in which the details - as free complements - add extra weight to the central elements by being put just before the central subject at the very beginning of the first sentence.

Pale and with a frightened expression in her eyes beneath her dark, smooth and shoulder-long hair, the very young school-girl arrived at the Courthouse of Odense where yesterday she had to tell the court how in the spring four young foreigners had raped her in turn in a backyard in the middle of town. (Ekstra Bladet, 8.8.01, p. 5)

As a content element the detail communicates proximity, identification and fascination. As a communication act it functions as documentation. Apart from that, the detail may in some contexts have a symbolic function ${ }^{4}$, so that the reader's contact with a deeper theme in the article is strengthened. 
In news journalism we meet the use of expressive details in several articles with narrative openings. The purpose is to create proximity in the report by exposing a person, a piece of information or a small event:

When 5 year-old Nanna puts the new pink school bag on her back for the first time today and gets ready to start preschool she will - unlike her new classmates - be homeless. (Ekstra Bladet, 7.8.01, p. 8)

The above two text samples demonstrate the difference between a detail based on observation and one based on experience. In the first case the journalist - as an observer - gets his detail from a situation in which he is actually present, observing and describing. In the second case the technique is used to visualize the detail in a way the journalist hardly has a chance to verify. This type of construction is widespread in written news. It is produced at the desk, where it often comes very close to pure fiction:

It was many years ago that Granddad had naughty postcards with pornographic pictures stashed well away, which he could then get when Grandma was off to church Sunday morning. (Ekstra Bladet, 8.8.01), p. 14)

Canada is shocked by a doping scandal, which has instantly shot down all dreams of being the perfect World Cup host. (B.T. 8.8.01, Sporten, p. 9)

\section{(8) Re-narration}

As a narrator the journalist has the possibility of summing up his story so that professionally complicated and heavy information appears more simple and easy to read. To prevent this diegetic mood of narration from appearing too superficial, the narrator may at the same time attempt to strengthen the truth-value of his summary by linking it to a reference, which is a documentative act of communication (cf. figure 1). As a consequence, the introductory reports appear in contexts in which references to sources are made; but the announcements are not presented as identifiable quotations or reports. The statements from the sources in such instances are integrated into the narrator's own summary:

Nightly bed-wetting is a hereditary disease. A nearly completed Danish PhD project shows that the two most common causes of the disease - a too-small bladder and too-great urine production - are hereditary. (Politiken, 9.8.01, p. 1)

The rule that care staff is not allowed to visit elderly people in their care during their leisure time is legally sound. So states expert of administrative law Oluf Jørgensen, who is head of department at the Danish School of Journalism after Copenhagen's municipal administration transferred a domestic helper because he got too close to his client. (Politiken, 9.8.01, p. 2)

\section{(9) Characterization}

Seldom does the narrator begin the first paragraph with a characterization that makes an interpretation on behalf of the reader. It may happen on rare occasions, however, especially in gossip notes.

The narrator in these cases attempts to secure credibility by weakening the impression of the report being an allegation (cf. the logical subject of linguistic details as 'could not be' and 'perhaps'): 
It could not be more symbolic for Nicole Kidman and Tom Cruise. While their marriage was annulled yesterday, they both attended opening nights the day before yesterday. (B.T., 9.8.01, p. 8)

A morbid desire for attention was perhaps the motive when a female kindergarten teacher at the Egmontgården kindergarten in Østerbro, Copenhagen invented telephone calls with death threats and wrote 'DIE' on the foreheads of five sleeping children. (B.T., 9.8.01, p. 8)

\section{Conclusion}

The qualitative analysis of the case material has provided a background for discussing a new picture of news journalism as a relatively source-independent and communication-oriented rewriting of incoming news material. From this point of view, news is not only edited information, anonymously organized and rewritten on a base of common editorial priority principles.

News is essentially narrated, i.e. constructed by a personally involved, individual journalist performing a role as an engaged narrator using a variation of communication acts and aiming at an understandable, reliable and interesting deliverance of the message.

The result of the analysis may be summarized in the following points:

1) Announcements are the most widely used and dominating communication acts in introductory paragraphs of news articles. They are mostly anonymous, i.e. communicated without a personal voice that expresses opinion, attitude, engagement or empathy and without direct reference to sources. By means of the syntactical structure of the first sentence, through an announcement the writer has the possibility to emphasise the chosen angle and focus of the story. This way of narration is the background for the concept of announced news in newspapers.

2) Alongside and continuously connected with announced news we find explicitly narrated news, whereby a narrator more or less openly and by means of various narrative techniques shows the personal character of his involvement in the news story. It may reveal itself as empathic identification with the main source of the story and as a use of the third-person point of view. The narrator may also construct an image, which in a brief and effective way communicates the most important information of the story. This image may be based on concrete observations or - more fictionally oriented - on experience. Narrated news - or as you may call it, soft news - is a central supplement of figure 1, in so far as you may meet mimetic acts in the first paragraphs of narrated news.

3) The list of qualitative observations is not exhaustive, but thus far the observations have documented a widespread use in news journalism of an explicitly marked narrator. Special attention should be given to the use of metaphors. They provide the narrator with an extensive array of possibilities for formations of meaning, be it trivial or original. The use of metaphors in journalism has a mainly exposing function. They produce and deliver understanding of factual information in nutshells and by means of fictional devices.

4) There seem to be variations between the individual media in that Politiken and Ekstra Bladet, to a higher degree than Berlingske Tidende, Morgenavisen Jyllands-Posten and B.T., make use of the existing possibilities of an explicitly narrative communi- 
cation of news. You may also say that Politiken and especially Ekstra Bladet have a more free way of narrative acting, whereas the other three seem to feel more restricted as narrative performers in the public sphere. The same variation may be seen between the editorial offices at the same paper. Articles about sports and industrial affairs, for example, seem to use different narrative codes. This points to some differences of discourse, which should be explored further.

\section{Notes}

1. The Republic, Book III, pp.392-395. Danish edition by Høeg and Ræder (1934), vol. IV, p. 113, ff.

2. Cf. Grunwald et al. (1992), p. 53 and Rich (1997), p. 77.

3. Cf. especially Lakoff and Johnson (1980), who introduce the concept of 'metaphors we live by' through analysis of a vast number of examples.

4. Cf. Grunwald et al. (1992), p. 72 and 74.

\section{References}

Alfvegren, Lars (1965) Tidningssvenska. Stockholm: Almqvist \& Wiksell.

Alfvegren, Lars (1973) Skriv så här: Råd, regler och rekommendationer i språkliga frågor. Stockholm: Almqvist \& Wiksell.

Alfvegren, Lars (1976) Språket i spalterne. Lund: Studentlitteratur.

Aristotle (1965) On the Art of Poetry. In Dorsch, T. S. (ed.) Classical Literary Criticism. Harmondsworth Middlesex, New York: Penguin Books, pp. 29-75.

Austin, J.L. (1962) How to do Things with Words. Oxford: The Clarendon Press.

Bech-Karlsen, Jo (1984) Avisreportasjen. Oslo: Universitetsforlaget.

Bech-Karlsen, Jo (1988) Feature-reportasjen. Oslo: Universitetsforlaget.

Bech-Karlsen, Jo (2000) Reportasjen. Oslo: Universitetsforlaget.

Genette, Gérard (1972) Narrative Discourse. An Essay In Method. Ithaca, New York: Cornell University Press.

Genette, Gérard (1988) Narrative Discourse Revisited. Ithaca, New York: Cornell University Press (translation Lewin, J.E.).

Grunwald, Ebbe (2003) Avisnyheders narrative fundament. Nordicom Information, 2003 (3), pp. 69-82.

Grunwald, Ebbe, Gert Smistrup \& Hans Veirup (1992) Journalistens sprog. Med et sprogligt serviceeftersyn. Århus: Ajour.

Hultén, Britt (2000) Journalistikanalys. Lund: Studentlitteratur.

Hultén, Lars J. (1990) Reportaget som kom av sig. Stockholm: Institutionen för Journalistik, Medier och Kommunikation.

Hvid, Mikkel (2002) Fascinerende fortcelling - Den journalistiske feature. Århus: CFJE.

Høeg, Carsten \& Hans Ræder (red.) (1934) Platons Skrifter i Overscettelse. Bd. 4. København: C. A. Reitzels Forlag.

Lakoff, George \& Mark Johnson (1980) Metaphors We Live by. Chicago: The University Chicago Press.

Meilby, Mogens (1996) Journalistikkens grundtrin. Fra ide til artikel. Århus: Forlaget Ajour.

Nerman, Bengt (1973) Massmedieretorik. Stockholm: Almqvist \& Wiksell.

Nylund, Mats (2003) Quoting in Front-page Journalism: Illustrating, Evaluating and Confirming the News. Media Culture \& Society, 25, pp. 844-851.

Rahm, Henrik (2001) Journalistikens anatomi. Analyser af genrer och textmönster i fem strejkbevakningar i svensk dagspress 1879-1996. Lund: Institutionen för Nordiska Språk.

Rich, Carold (1997) Writing and Reporting News. A Coaching Method. New York: Wadsworth Publishing Company.

Roksvold, Thore (1989) Retorikk for journalister. Otta: J.W. Cappelens Forlag.

Searle, John R. (1970) Speech Acts. An Essay in The Philosophy of Language. Cambridge: The University Press.

Searle, John R. (1971) What is a Speech Act? In J.R. Searle (red.) The Philosophy of Language. London: Oxford University Press, pp. 39-53.

Skyum-Nielsen, Peder (red.) (2002) Stcerkere journalistik. Odense: Syddansk Universitetsforlag.

Skyum-Nielsen, Peder (2003) Vellyden. Odense: DR Multimedie og Syddansk Universitetsforlag. 
Thurén, Torsten (1992) Reportagets rika repertoar. Stockholm: Inst. för Journalistik, Medier och Kommunikation.

Veirup, Hans, Gert Smistrup \& Ebbe Grunwald (1973) Det sproglige Serviceeftersyn. Århus: Institut for Presseforskning. 